\title{
THE EURO AND INFLATION UNCERTAINTY \\ IN THE EUROPEAN MONETARY UNION
}

\author{
Guglielmo Maria Caporale* \\ Brunel University, London
}

\author{
Alexandros Kontonikas \\ University of Glasgow
}

January 2006

\begin{abstract}
In this paper, we investigate empirically the relationship between inflation and inflation uncertainty in twelve EMU countries. We estimate a time-varying parameter model with a GARCH specification for the conditional volatility of inflation in order to distinguish between short-run (structural and impulse) and steady-state uncertainty. We then introduce a dummy variable to model the policy regime shift which occurred in 1999 with the introduction of the Euro, and its effects on the links between inflation and inflation uncertainty. We find that steady-state inflation has generally remained stable (with the important exception of Germany, where the trend has become positive), steady-state inflation uncertainty and inflation persistence have both increased, and the relationship between inflation and inflation uncertainty has broken down in many countries. These findings cast doubt on the optimistic view taken by the ECB concerning its success in controlling inflation, and suggest the need for improvements in its analytical framework.
\end{abstract}

JEL classification: E31; E52; C22

Keywords: Inflation, Inflation Uncertainty, Inflation Persistence, Time-Varying Parameters, GARCH models, ECB, EMU

We are grateful to Zubeyir Kilinc for providing the Matlab routines for the estimation. Special thanks are due to Michael Arghyrou for his insightful suggestions. We have also greatly benefited from useful comments from Mustafa Caglayan, Jagit Chadha, Andrea Cipollini, John Hunter, Menelaos Karanasos, and Chris Tsoukis. The usual disclaimer applies.

Corresponding author: Professor Guglielmo Maria Caporale, Brunel Business School, Brunel University, Uxbridge, Middlesex UB8 3PH, UK. Tel.: +44 (0)1895 266713. Fax: +44 (0)1895 269770. Email: Guglielmo-Maria.Caporale@,brunel.ac.uk 


\section{Introduction}

The introduction of the euro and of a common monetary policy in 1999 undoubtedly represented a major policy regime shift for the member countries of the European Monetary Union (EMU). This could have affected both inflation expectations and inflation uncertainty, as, at least initially, agents might not have been certain of the objective function and the policy preferences of the European Central Bank (ECB), and of how they might compare to those of the national central banks previously in charge of monetary policy (for instance, the ECB might have been perceived as less credible than the Bundesbank, which had an established antiinflation reputation). Uncertainty about the policy preferences of the new monetary authorities might also result in higher inflation forecast errors. According to the Maastricht Treaty, although the primary objective of the ECB is price stability (which the ECB has interpreted as an annual Euro area inflation rate below, but close to, $2 \%$ in the medium run), it should also be concerned about output and employment (albeit without prejudicing its main objective). The monetary policy framework adopted by the ECB to fulfil these tasks is based on two analytical perspectives or two "pillars", namely economic analysis and monetary analysis ${ }^{1}$, and the ECB has repeatedly stated that achieving price stability is the most effective way to contribute to output and employment growth (see, e.g. Monetary Policy Strategy, 1999), but nevertheless higher uncertainty might have characterised the new economic environment.

Analysing survey data, Heinemann and Ullrich (2004) do not find significant differences in the inflationary credibility of the ECB compared to the Bundesbank, and hence no permanent change in inflation expectations. However, their analysis suggests that the higher uncertainty characterising the period leading up to EMU led to a temporary change in expectation formation, with agents relying more heavily on backward-looking expectations, before reverting to the normal mechanisms once the ECB had established its inflation credibility.

\footnotetext{
${ }^{1}$ Economic analysis aims at assessing the short- to medium-term determinants of price developments focusing on real activity and financial conditions in the economy. Monetary analysis focuses on a longer-term horizon taking into account the long-run relationship between money and prices. A reference value of $4.5 \%$ for the growth rate of broad money (M3) that is compatible with price stability has been calculated using the quantity theory equation. The ECB has stated, though, that "monetary policy does not react mechanically to deviations of M3 growth from the reference value" (see The Monetary Policy of the ECB, 2004). As Rudebusch and Svensson $(1999$, p.1) point out, the ECB strategy "appears to be a combination of a weak type of monetary targeting and an implicit form of inflation targeting".
} 
As for inflation uncertainty, in a recent review of the performance of the ECB in the first few years of the new regime, its President, Jean-Claude Trichet, has expressed the view that "... the ECB has, despite substantial adverse price shocks, successfully kept inflation and inflation expectations at low levels by historical standards. The single monetary policy and its clear focus on the maintenance of price stability have helped to anchor inflation expectations in the euro area over the medium and the long term. This has facilitated a reduction of inflation uncertainty and the associated risk premia" (see Trichet, 2004).

In this paper, we analyse empirically how the new policy regime with the ECB setting a common interest rate for the EMU countries has in fact affected inflation uncertainty and, consequently, inflation itself in the Euro area adopting an appropriate econometric framework. Specifically, we use a time-varying model with a GARCH specification for the conditional volatility of inflation, as in Evans (1991), and obtain estimates for twelve EMU countries, over the period 1973-2004, using monthly data. The adopted framework enables us to distinguish between different types of inflation uncertainty which can affect the inflation process. Our aim is to establish whether the ECB has been as successful as claimed by its President, Mr. Trichet, in creating a less inflationary environment. For this purpose, we focus on the policy regime shift which occurred in 1999, which is modelled by introducing in the estimated models a step dummy corresponding to the adoption of the Euro. In particular, we investigate four issues, namely whether and how the introduction of the Euro has affected: a) steady-state inflation; b) steady-state inflation uncertainty; c) inflation persistence; d) the relationship between inflation and inflation uncertainty.

The layout of the paper is the following. Section 2 reviews the relevant literature. Section 3 outlines the empirical framework. Section 4 presents the empirical results. Section 5 interprets them with a view to assessing the validity of Mr Trichet's statement on the ECB's successful experience in controlling inflation. Section 6 summarises the main findings and discusses their policy implications.

\section{A Brief Literature Review}

The relationship between inflation and inflation uncertainty has received increased attention in recent years. Friedman (1977) first argued that higher average inflation would result in more inflation uncertainty. This idea was developed by Ball 
(1992): in his model, in the presence of two types of policymakers with different preferences, who stochastically alternate in power, higher inflation generates higher inflation uncertainty, as agents do not know when monetary authorities with a tougher stance on inflation will replace the current ones. Causality in the opposite direction, namely from inflation uncertainty to inflation, is instead a property of models based on the Barro-Gordon setup, such as the one due to Cukierman and Meltzer (1986), in which there is an incentive for policymakers to create inflation surprises to raise output growth. ${ }^{2}$

A number of empirical studies have investigated this relationship, normally adopting an econometric framework of the GARCH type (see Engle, 1982), and providing mixed evidence (see Davis and Kanago, 2000 for a survey). For instance, Grier and Perry (1998) estimate GARCH models to generate a measure of inflation uncertainty, and then carry out Granger causality tests. Using data for the G7 countries, they find strong evidence of causality running from inflation uncertainty to inflation, but less empirical support for causality in the opposite direction (see also Baillie et al, 1996). Various studies focus on the US, again with mixed results. Brunner and Hess (1993), and Grier and Perry (1998, 2000), inter alia, find evidence of a Friedman effect, with Baillie et al (1996) reporting the opposite. More recently, the impact of inflation targeting on this relationship has been analysed. Kontonikas (2004) reports that the adoption of an explicit target in the UK has resulted in lower inflation persistence and long-run uncertainty. Fountas et al (2004) argue that in the context of EMU the linkages between inflation, inflation uncertainty and output growth have even more important implications for monetary policy, since price stability becomes an even more crucial policy objective for the ECB if inflation is found to affect inflation uncertainty. Further, asymmetries in the effects of inflation uncertainty on output across member countries could make a common monetary policy a less effective stabilisation tool. In fact their empirical analysis, based on EGARCH models, provides evidence supporting the Friedman hypothesis and the presence of asymmetric real effects. However, their sample period is 1960-1999, and hence does not include the new monetary policy setting resulting from the introduction of the euro, whose effects on inflation we wish to examine. Further, their analysis does not distinguish between different types of inflation uncertainty, whilst the approach taken in the present study, as explained below, enables us to

\footnotetext{
${ }^{2}$ Note that the effect of inflation on its uncertainty can also be negative (see Fountas and Karanasos,
} 
measure separately the impact of short-run (structural and impulse) and long-run uncertainty. $^{3}$

\section{Econometric Framework}

According to Pagan (1984), simultaneous conditional mean and variance estimation as in a GARCH-in-mean (GARCH-M) model is more efficient than a two-step approach where the conditional variance is estimated first using a GARCH specification, and then included in the conditional mean equation to carry out causality tests. For this reason, a GARCH-M model is estimated by Kontonikas (2004). However, as pointed out by Grier and Perry (1998) and Fountas et al (2004), this approach has the drawback that it does not allow the testing of possible lagged effects of inflation uncertainty on inflation, which might exist at the monthly or quarterly frequency; for this reason, these authors use two-step procedures instead, as we also do (see below). ${ }^{4}$

It should be noted as well that conventional GARCH models impose a symmetry restriction on the conditional variance. As highlighted by Brunner and Hess (1993), this is inconsistent with the Friedman hypothesis, which implies that new information leading to a downward revision of inflation expectations should also lower inflation uncertainty. Models allowing for an asymmetric impact of news on inflation uncertainty include the EGARCH model of Nelson (1991), which, in contrast to standard GARCH specifications, does not impose non-negativity constraints on the parameter space (this approach is taken by Fountas et al, 2004); the Threshold GARCH (TGARCH) model of Zakoian (1994) and Glosten et al (1993), and the component GARCH (CGARCH) model of Engle and Lee (1993) (both these models are estimated by Grier and Perry, 1998, and Kontonikas, 2004). The CGARCH model has the additional advantage of decomposing inflation uncertainty into a short-run and a long-run component by permitting transitory deviations of the conditional volatility around a time-varying trend.

All the methods discussed above have the drawback that they do not take into account the fact that uncertainty about the long- and short-term prospects for inflation might differ significantly and affect inflation expectations in different ways.

2006, for a review of relevant studies).

${ }^{3}$ Another strand of the literature analyses the relationship between inflation and its uncertainty using long-memory models (see Conrad and Karanasos, 2006). 
As emphasised by Evans (1991), agents' temporal decisions are more likely to be affected by the conditional variance of short-run movements in inflation, whilst intertemporal decisions might be based mainly on changes in the conditional variance of long-term inflation. Moreover, one should distinguish between "structural uncertainty" (associated with the randomness in the time-varying parameters, and representing the propagation mechanism), which might originate, for instance, from unanticipated monetary policy changes, and "impulse uncertainty" (associated with the shocks hitting the conditional variance, which are propagated through the parameters of the inflation process), reflecting, for example, changes in the variance of structural disturbances such as price shocks (see Berument et al, 2005).

The econometric framework suggested by Evans (1991), and also adopted by Berument et al (2005) in their analysis of the linkages between inflation uncertainty and interest rates, has the advantage over alternative approaches of yielding estimates of the various types of uncertainty discussed above. Following these authors, in the present study we also utilise a GARCH model with time-varying parameters, which are estimated using Kalman filtering. More specifically, inflation is specified as a $k$-th order autoregressive process, $\operatorname{AR}(k)$, with time-varying parameters, the residuals of this equation following a $\operatorname{GARCH}(p, q)$ process. ${ }^{5}$ The model is the following:

$$
\begin{aligned}
& \pi_{t+1}=\mathbf{X}_{\mathbf{t}} \boldsymbol{\beta}_{\mathbf{t}+\mathbf{1}}+e_{t+1} \quad \text { where } \quad e_{t+1} \square N\left(0, h_{t}\right) \quad \text { and } \quad \mathbf{X}_{\mathbf{t}}=\left[1, \pi_{t}, \ldots, \pi_{t-k}\right] \\
& h_{t}=h+\sum_{i=1}^{q} a_{i} e_{t-i}^{2}+\sum_{j=1}^{p} \lambda_{j} h_{t-j} \\
& \boldsymbol{\beta}_{\mathbf{t}+\mathbf{1}}=\boldsymbol{\beta}_{\mathbf{t}}+\mathbf{V}_{\mathbf{t}+\mathbf{1}} \quad \text { where } \quad \mathbf{V}_{\mathbf{t}+\mathbf{1}} \square N(\mathbf{0}, \mathbf{Q})
\end{aligned}
$$

\footnotetext{
${ }^{4}$ Fountas et al (2004) also report the estimation results of an EGARCH-M model, which confirm the fact that a simultaneous approach does not detect the causal effect of inflation uncertainty on inflation. ${ }^{5}$ Evans and Wachtel (1993) stress that the assumption of fixed parameters in the inflation process overestimates the degree to which agents can forecast inflation, and consequently underestimates inflation uncertainty. They decompose the sources of inflation uncertainty into two components: "regime uncertainty component" and "certainty equivalence component". The second component ignores uncertainty about future inflation regimes and reflects only the variance of future shocks to the inflation process. The first component reflects the agents' uncertainty about the characteristics of the current policy regime or even future regimes, if there is a possibility that the regime will change. Thus, cross-counties differences in the conduct of monetary policy may account for the differences in the average levels of uncertainty. This decomposition allows inflation uncertainty to change over time as agents keep updating their information on the current regime and their expectations about the future regime. See also the comment by Brunner (1993).
} 
where $\pi_{\mathrm{t}+1}$ denotes the rate of inflation between $t$ and $t+1 ; \mathbf{X}_{\mathbf{t}}$ is a vector of explanatory variables known at time $t ; e_{t+1}$ describes the shocks to the inflation process that cannot be forecast with information known at time $t ; e_{t+1}$ is assumed to be normally distributed with a time-varying conditional variance $h_{t}$. The conditional variance is specified as a $\operatorname{GARCH}(p, q)$ process, that is, as a linear function of past squared forecast errors, $e_{t-i}^{2}$, and past variances, $h_{t-j}$. Further, $\boldsymbol{\beta}_{\mathbf{t + 1}}=\left[\beta_{0, t+1}, \beta_{1, t+1}, \ldots, \beta_{k, t+1}\right]$ denotes the time-varying parameter vector, and $\mathbf{V}_{\mathbf{t + 1}}$ is a vector of shocks to $\boldsymbol{\beta}_{t+1}$, assumed to be normally distributed with a homoscedastic covariance matrix $\mathbf{Q}$. The updating equations for the Kalman filter are:

$$
\begin{aligned}
& \pi_{t+1}=\mathbf{X}_{\mathbf{t}} E_{t} \boldsymbol{\beta}_{\mathbf{t}+\mathbf{1}}+\varepsilon_{t+1} \\
& H_{t}=\mathbf{X}_{\mathbf{t}} \boldsymbol{\Omega}_{\mathbf{t}+\mathbf{1} \mid \mathbf{X}} \mathbf{X}_{\mathbf{t}}^{\prime}+h_{t} \\
& E_{t+1} \boldsymbol{\beta}_{\mathbf{t}+2}=E_{t} \boldsymbol{\beta}_{\mathbf{t}+1}+\left[\boldsymbol{\Omega}_{\mathbf{t}+1 \mid \mathbf{t}} \mathbf{X}_{\mathbf{t}}^{\prime} H_{t-1}\right] \varepsilon_{t+1} \\
& \boldsymbol{\Omega}_{\mathbf{t}+2 \mid \mathbf{t}+1}=\left[\mathbf{I}-\boldsymbol{\Omega}_{\mathbf{t}+\mathbf{1} \mid \mathbf{t}} \mathbf{X}_{\mathbf{t}}^{\prime} H_{t-1} \mathbf{X}_{\mathbf{t}}\right] \boldsymbol{\Omega}_{\mathbf{t}+\mathbf{t} \mid \mathbf{t}}+\mathbf{Q}
\end{aligned}
$$

where $\boldsymbol{\Omega}_{\mathbf{t + 1 | \mathbf { t }}}$ is the conditional covariance matrix of $\boldsymbol{\beta}_{\mathbf{t}+\mathbf{1}}$ given the information set at time $t$, representing uncertainty about the structure of the inflation process.

As Eq. (5) indicates, the conditional variance of inflation (short-run uncertainty), $H_{t}$, can be decomposed into: (i) the uncertainty due to randomness in the inflation shocks $e_{t+1}$, measured by their conditional volatility $h_{t}$ (impulse uncertainty); (ii) the uncertainty due to unanticipated changes in the structure of inflation $\mathbf{V}_{t+1}$, measured by the conditional variance of $\mathbf{X}_{t} \boldsymbol{\beta}_{t+1}$, which is $\mathbf{X}_{\mathbf{t}} \boldsymbol{\Omega}_{\mathbf{t}+1 \mid \mathbf{t}} \mathbf{X}_{\mathbf{t}}^{\prime}=S_{t}$ (structural uncertainty). The standard GARCH model can be obtained as a special case of our model if there is no uncertainty about $\boldsymbol{\beta}_{t+1}$, so that $\boldsymbol{\Omega}_{\mathbf{t}+\mid \mathbf{t}}=\mathbf{0}$. In this case, the conditional variance of inflation depends solely on impulse uncertainty ${ }^{6}$. Eqs. (6) and (7) capture the updating of the conditional distribution of $\boldsymbol{\beta}_{\mathbf{t}+\mathbf{1}}$ over time in response to new information about realised inflation. As indicated by Eq. (6), inflation innovations, defined as $\varepsilon_{t+1}$ in Eq. (4), are used to update the estimates of $\boldsymbol{\beta}_{t+1}$. These estimates are then used to forecast future inflation. 
If there are no inflation shocks and parameter shocks, so that $\pi_{t+1}=\pi_{t}=\ldots=\pi_{t-k}$ for all $t$, we can calculate the steady-state rate of inflation, $\pi_{t+1}^{*}$, as:

$\pi_{t+1}^{*}=\beta_{0 . t+1}\left[1-\sum_{i=1}^{k} \beta_{i . t+1}\right]^{-1}$

The conditional variance of steady-state inflation is then given by:

$\sigma_{t}^{2}\left(\pi_{t+1}^{*}\right)=\nabla E_{t} \boldsymbol{\beta}_{\mathbf{t}+1} \boldsymbol{\Omega}_{\mathbf{t}+\mathbf{1} \mid \mathbf{t}} \nabla E_{t} \boldsymbol{\beta}_{\mathbf{t}+\mathbf{1}}^{\prime}$

where $\nabla E_{t} \boldsymbol{\beta}_{\mathbf{t}+\mathbf{1}}^{\prime}=\left[\begin{array}{c}\left(1-\sum_{i=1}^{k} E_{t} \beta_{i . t+1}\right)^{-1} \\ E_{t} \beta_{0 . t+1}\left(1-\sum_{i=1}^{k} E_{t} \beta_{i . t+1}\right)^{-2} \\ \ldots \\ E_{t} \beta_{0 . t+1}\left(1-\sum_{i=1}^{k} E_{t} \beta_{i . t+1}\right)^{-2}\end{array}\right] \quad$ is a $(k+1 x 1)$ vector.

Having computed short-run and steady-state uncertainty measures for each country, we then proceed, in the second part of our empirical investigation, to analyse the links between the various types of inflation uncertainty and the level of inflation, as well as to examine the impact of the Euro. Specifically, we regress month-to-month changes in the two uncertainty measures against changes in past inflation $^{7}$. Moreover, we include a dummy variable to allow for possible intercept and slope changes in the underlying relationship between inflation uncertainty and past inflation reflecting the introduction of the Euro. The estimated model is the following:

$$
\Delta u n c_{t+1}=\gamma_{0}+\gamma_{1} D_{t+1}+\left(\gamma_{2}+\gamma_{3} D_{t+1}\right) \Delta \pi_{t}+\theta_{t+1}
$$

\footnotetext{
${ }^{6}$ As Evans (1991) argues, if there is uncertainty about $\beta_{t+1}, h_{t}$ will tend to understate the true conditional variance since $\mathrm{S}_{\mathrm{t}}>0$.

${ }^{7}$ As Evans (1991, p. 180) notes, "the regressions use the month-to-month changes in the variances and inflation because inflation has a unit root and all three variances are complicated functions of past inflation".
} 
where $u n c_{t+1}$ represents in turn steady-state uncertainty (i.e. $\left.\sigma_{t}^{2}\left(\pi_{t+1}^{*}\right)\right)$ and short-run uncertainty (i.e., $H_{t}$ ), and $D_{t+1}$ is a dummy variable equal to zero during the preEuro period and one during the Euro period. ${ }^{8}$

\section{Empirical Analysis}

Inflation is measured as the first difference of the logarithm of the seasonally adjusted consumer price index $(\mathrm{CPI}), \pi_{t+1}=100 *\left(\ln C P I_{t+1}-\ln C P I_{t}\right)$, using monthly data for twelve EMU countries (Germany, France, Italy, Spain, Portugal, Greece, Ireland, Finland, Belgium, Netherlands, Luxembourg, Austria) over the period 19732004. Six years of the Euro period are included in our sample ${ }^{9}$, allowing us to study the effects of the 1999 policy regime shift on inflation uncertainty over a reasonably long horizon. The data are obtained from OECD's Main Economic Indicators: Historical Statistics.

Table 1 reports the results from ADF (see Dickey and Fuller, 1979, 1981) and KPSS (see Kwiatkowski, Phillips, Schmidt, and Shin, 1992) unit root tests with an intercept and a deterministic linear trend. Overall, the results suggest that inflation in our sample countries has a unit root, which can justify our choice of a random walk model for the time-varying parameters of the inflation process (see Evans, 1991). In a recent paper, Rapach and Weber (2004) also find that inflation is non-stationary using a sample of OECD countries and a variety of unit root testing procedures.

[Table 1 about here]

[Figure 1 about here]

We have estimated a time-varying GARCH model for inflation with Kalman filtering, as described in section 3. Figures 1-3 are based on the estimation results. ${ }^{10}$ Figure 1 plots actual inflation and steady-state inflation in the EMU countries over the period 1980.01-2004.11. In the early years of the new monetary regime the Euro area was affected by a variety of price shocks such as the tripling of oil prices

\footnotetext{
${ }^{8}$ In the case of Finland, where inflation targeting was adopted over the period 1993-1998, we also included intercept and level dummies for this policy change, but these turned out not to be statistically significant.

${ }^{9}$ As Greece adopted the Euro only in January 2001, the corresponding sub-sample is four years.
} 
between early 1999 and mid-2000, the depreciation of the common currency over this period, and finally, in 2001, significant increases in food prices, due to a series of livestock epidemics. This is evident across the EMU countries in the plots of actual inflation. Average monthly inflation rates vary considerably in the EMU area, ranging from $0.2 \%$ in Germany to $1 \%$ in Greece. Similarly to the former country, mean monthly inflation rates in the Benelux countries (Belgium, Netherlands, Luxembourg) and Austria were low: $0.26 \%, 0.21 \%, 0.26 \%$ and $0.23 \%$, respectively. Steady-state inflation follows similar patterns, with Greece exhibiting the worst performance, with an annualised steady-state inflation rate of $12 \%$, while in Germany the corresponding value was 2.5\%. Busetti et al (2006) also present evidence of diverging behaviour in the inflation rate of the EMU countries since 1999. Such inflation differentials are often found even within monetary unions, where many economic differences may survive. The ECB itself admits that "monetary policy can only influence the price level of the Euro area as a whole and cannot affect inflation differentials across regions" (see The Monetary Policy of the $E C B, 2004)$. Nevertheless, from the viewpoint of monetary policy effectiveness in stimulating economic growth, inflation rates in EMU countries should converge in order for changes in the Euro-wide nominal interest rate to be translated into similar real interest rate changes across member countries.

[Figure 2 about here]

Figure 2 plots short-run uncertainty and steady-state uncertainty. The former appears to have decreased over time along with average inflation in Portugal and Greece, while in France it has increased. In Italy, Spain, Ireland and Finland one can identify large increases in short-run uncertainty in the first part of the 1980s followed by a relatively stable period. In Germany a large temporary increase in short-run uncertainty can be noticed around the time of the re-unification in the early 1990s. Short-run uncertainty in the Netherlands and Austria is relatively stable, apart from occasional temporary shocks. The same applies to Luxembourg, with the exception of a large temporary jump in 1999. It should be pointed out that some short-term volatility in inflation is inevitable given the fact that monetary policy can only affect

\footnotetext{
${ }^{10}$ The estimated parameters for each country are not presented to save space, but are available from the authors upon request.
} 
prices with long and uncertain lags - hence the focus of the ECB on medium-term price stabilisation.

Regarding the uncertainty associated with long-run inflation, it appears again that a uniform experience did not occur, since steady-state uncertainty seems to increase towards the end of the sample period in Germany, Italy, Spain, Portugal, Luxembourg and Austria, while in France, Ireland, Finland and Belgium it declines over time. Only in the Greek case does the uncertainty associated with steady-state inflation increase steadily throughout the sample period. ${ }^{11}$ Clearly, the presence of such significant differentials across the countries of the Euro area in terms of longrun (as opposed to short-run) uncertainty has important policy implications, given the focus of the ECB on maintaining price stability in the Euro area over longer periods of time.

[Figure 3 about here]

Figure 3 plots inflation persistence (the sum of the estimated autoregressive coefficients in the inflation specification) and the trend component of inflation (the estimated constant in the inflation process). The former increases over time in Germany, Italy, Spain and Austria. This is in line with previous work by Angeloni et al (2005) finding that inflation persistence in the Euro area did not decline after the introduction of the Euro. Batini (2002) also shows that inflation in the Euro area is inertial using the autocorrelation function of inflation and the lag in the inflation response to monetary policy shocks from VAR's to measure inflation persistence. Our results show that in some cases (Finland, Belgium, Netherlands, Luxembourg) inflation persistence becomes negative. This can be interpreted in terms of an errorcorrection mechanism in inflation: as inflation grows large, the central bank adopts tougher anti-inflationary policies. Trend inflation decreases over time in the majority of the sample countries, reflecting the general move towards lower inflation after the highly inflationary 1970 s.

[Table 2 about here]

\footnotetext{
${ }^{11}$ One possible explanation is the failure on the part of the Greek authorities to implement overdue structural changes to the economy, resorting instead to "creative" accounting practises to hide the true
} 
Table 2 reports robust estimates of the parameters of Eq. (11) (see Newey and West, 1994). Consistently with the hypothesis put forward by Friedman (1977) and formalised by Ball (1992), the coefficient of past inflation, $\gamma_{2}$, is positive and significant in six out of our twelve sample countries in the steady-state uncertainty regressions, i.e. in the case of France, Italy, Portugal, Belgium, Luxembourg and Austria. When the change in short-run uncertainty is employed as a dependent variable, $\gamma_{2}$ is significantly positive in five instances, i.e. in Germany, France, Portugal, Greece and Ireland ${ }^{12}$. This suggests that, by lowering average inflation, monetary authorities can reduce the negative consequences of inflation uncertainty.

As for the impact of the Euro and common monetary policy on inflation uncertainty, we find that the coefficient of the intercept dummy, $\gamma_{1}$, is positive and statistically significant for Italy and Austria in the steady-state regressions, indicating that steady-state uncertainty has increased in the Euro period in these countries. The coefficient of the slope dummy, $\gamma_{3}$, is negative and statistically significant in eight countries (Germany, France, Italy, Spain, Greece, Belgium, Luxembourg, Austria) in the steady-state regressions and in three countries (Germany, Greece, Ireland) in the short-run regressions. This indicates an important change in the underlying relationship between inflation and uncertainty occurring in these countries as a result of the introduction of the Euro, since a negative and significant $\gamma_{3}$ implies that in the Euro period further reductions in average inflation increase, rather than reduce, uncertainty. The Wald F-statistic for the null hypothesis: $\gamma_{2}+\gamma_{3}=0$, indicates that after the introduction of the Euro the relationship between past inflation and current short-run uncertainty breaks down in the case of Germany, Greece, and Ireland, while in the steady-state regressions the null hypothesis is not rejected in the case of Luxembourg and Austria. Thus, in many instances, the Friedman-Ball link that calls for policies aiming at low inflation in order to reduce the corresponding uncertainty appears not to exist in the Euro period. This finding may reflect the fact that inflation has been relatively low in all advanced economies since the 1990s, irrespective of whether or not an explicit inflation target was in place. Therefore, there might not be room for further reductions in average inflation, with the associated risk of generating deflationary pressures, and policies aimed at achieving even lower inflation may paradoxically result into higher uncertainty.

extent of their fiscal problems (see the report by the Commission of the European Communities, 2004).

12 This is in line with previous evidence for the UK (see Kontonikas, 2004). 


\section{Interpreting the Evidence}

To what extent are the empirical results discussed above consistent with $\mathrm{Mr}$. Trichet's opinion that the ECB has successfully brought inflation under control? To answer this question, in this section we evaluate the validity of his statement using the four criteria mentioned in the introduction, i.e. the effects of the Euro on: a) steady-state inflation; b) steady-state inflation uncertainty; c) inflation persistence; d) the relationship between inflation and inflation uncertainty.

With regard to steady-state inflation, our results generally support $\mathrm{Mr}$. Trichet's claim, as this variable appears to have remained stable; however, Germany, where the downward trend observed from 1992 appears to have been replaced by a positive one from the time of the introduction of the Euro, represents and important exception, this country having a special weight for the EMU project as a whole. This increase in German steady-state inflation may be due to the fact that ECB's monetary policy has in general been rather loose since 1990, and/or it might reflect the fact that Germany has failed to put her public finances right. Of course, one might argue that Germany's weak internal demand in recent years has resulted in a reduction in actual inflation, and it has been the cause, rather than the effect, of the ECB's loose monetary policy. This may be true, but it is not inconsistent with our results. Our analysis concerns steady-state inflation, i.e. inflation adjusted for the effects of the business cycle. An increase in German steady-state inflation is not inconsistent with low actual inflation in Germany. The latter (actual inflation) has two components, the steady-state and the business-cycle component. What our results imply is that Germany actual (total) inflation has stayed constant - this is entirely consistent with a state of affairs where one component (steady-state inflation) increases (due, for example, to long-run public finance difficulties), while the other component (business-cycle inflation) declines due to weak demand conditions. Hence in the case of Germany the optimism of Mr. Trichet may be overlooking some very important underlying problems.

As for the other EMU countries, although the evidence is consistent with Mr. Trichet's assessment, it is also true, as stressed above, that inflation in other nonEMU industrialised countries has remained stable at low levels over the last few years. As also noticed before, it is worth noting that there exist substantial differences in the level of steady-state (and actual) inflation among EMU countries 
(probably reflecting different degrees competition in the goods', capital and labour markets), which is a significant problem for the ECB and EMU in general. Although it is not the responsibility of monetary authorities policy to eliminate these differences, they undoubtedly exist and represent a significant challenge, whose seriousness is not duly emphasised in Mr. Trichet's comments.

Moving on to inflation uncertainty, our finding of higher steady-state inflation uncertainty in many EMU countries casts serious doubt on the validity of Trichet's view, as increased uncertainty is clearly not beneficial to an economy's long-term prospects. It is not entirely clear why inflation uncertainty has increased. One possibility is that this reflects the uncertainty surrounding the general future economic prospects of the Eurozone owing to a sustained low-growth period and/or lack of transparency of the monetary policy framework adopted by the ECB (the dual strategy of simultaneous monetary and inflation targets may confuse agents); alternatively, it may reflect a lack of transparency with regard to the policy preferences of the ECB, in the presence of different economic requirements on the part of the individual member states.

Concerning inflation persistence, the evidence again seems to contradict the optimism of Mr. Trichet. In particular, our empirical analysis can be interpreted as suggesting that, following the introduction of the Euro, individual countries have lost the flexibility independent monetary policy provided to them to reduce inflation quickly; consequently, inflation persistence has increased as a result of the lack of ability of individual countries to respond flexibly to their particular inflation dynamics. In brief, our finding of higher inflation persistence may be related to the basic argument against the Euro, i.e. that participating countries lose a useful policy tool (monetary policy) to manage their economies in the short- and medium-run.

Finally, the breakdown of the relationship between inflation and inflation uncertainty, which we find, is also important as it indicates that an important monetary policy mechanism, i.e. the effect that more stable inflation expectations has on actual inflation, may have been invalidated. This, together with the heterogeneity of our results (i.e. the fact that for some countries the relationship has broken down, for others it has not; for some it has broken down for actual inflation, for others for steady-state inflation), is yet another confirmation of the difficulties faced by the ECB in adopting a common monetary policy for a number of quite different individual 
countries, with different and perhaps divergent economic requirements. Why this relationship has broken down is also a moot point.

\section{Conclusions}

In this paper, we have investigated empirically the relationship between inflation and inflation uncertainty in twelve EMU countries. Following Evans (1991) and Berument et al (2005), we have adopted a time-varying GARCH specification to model the conditional volatility of inflation in order to be able to distinguish between short-run (structural and impulse) and steady-state uncertainty. We have also analysed the impact on the links between inflation and inflation uncertainty of the policy regime shift which occurred in 1999, when the Euro was introduced and the ECB was given the task of setting a common monetary policy for all EMU countries.

Our empirical findings can be summarised as follows. The inflation performance of the EMU member states has been very different over the whole period starting at the beginning of the 1980s, in terms of both actual and steady-state inflation. Similarly, no consistent pattern can be found for the degree of persistence of inflation. By contrast, as one would expect given the less inflationary environment prevailing after the inflation hike of the 1970s, trend inflation has generally become much lower. Concerning short-run and steady-state uncertainty, again the EMU countries appear to have had rather different experiences, with no clear picture emerging. Most interestingly and perhaps controversially, it appears that in many cases the introduction of the Euro has not been beneficial from the viewpoint of inflation uncertainty. In Austria and Italy, for example, we find a step increase in steady-state uncertainty following the adoption of the Euro. Moreover, in these and other six countries, i.e. Germany, Greece, France, Spain, Belgium and Luxembourg, it would seem that the pursuit of anti-inflationary policies by the ECB is counterproductive, in the sense that lower inflation might lead to higher steady-state uncertainty. The same applies to short-run uncertainty in the case of Germany, Greece and Ireland, where the Friedman-Ball link between inflation and inflation uncertainty is not found in the Euro period.

On the whole, one could conclude that the monetary policy of the ECB has not been an unqualified success as suggested by its President, Mr. Trichet. To answer the four questions posed at the beginning, we find that steady-state inflation has 
generally remained stable (with the important exception of Germany, where the trend has become positive), steady-state inflation uncertainty and inflation persistence have both increased, and the relationship between inflation and inflation uncertainty has broken down in many countries. This clearly suggests that the glowing assessment of the ECB's inflation performance made by Mr. Trichet requires some rethinking.

Although it is true that inflation has been relatively low in the EMU countries under the new regime, this also applies to all other OECD economies over the same period, and cannot obviously be attributed to the policy actions of the ECB. The case of Germany, a key EMU country, where steady-state inflation appears to have increased, obviously calls for special attention. Moreover, cross-country economic differences clearly still pose a stiff challenge to a common monetary policy. The higher steady-state inflation uncertainty, and the breakdown in the relationship between inflation and inflation uncertainty following the introduction of the Euro, suggest that in the new economic environment monetary policy might have become less effective in lowering inflation uncertainty, possibly as a result of conflicting economic and monetary signals, and lack of transparency in the two-pillar strategy employed by the ECB. As Bofinger (2002, p.11) argues, "In sum, while the first pillar is too narrowly focused on the money stock M3...the second pillar is much too broad to provide any guidance for the ECB's internal decisions or its dialogue with public". Rudebusch and Svensson (1999) also point out that emphasis on using movements in the stock of money as a rationale for policy is undesirable since it may result in higher inflation and output variability. The fact that lowering inflation expectations has become less effective as a way of controlling inflation is yet another indication of the difficulties faced by monetary policy in the context of a monetary union with widely different member countries. This lack of flexibility, owing to the loss of monetary policy independence for individual countries, might account for higher inflation persistence. Hence, although it should be kept in mind that the ECB is concerned with price stability of the Euro area as a whole, it appears that improvements could be made to its analytical framework with a view to lowering the estimated long-run uncertainty in individual member countries - for instance, a more explicit focus on the inflation forecast might be useful in this respect. 


\section{REFERENCES}

Angeloni, I., Aucremanne L. and M. Ciccarelli (2005), "Price setting and inflation persistence: did EMU matter?", European Central Bank, Paper published by the Inflation Persistence Network.

Baillie, R., Chung, C.F. and M. Tieslau (1996), "Analyzing inflation by the fractionally integrated ARFIMA_GARCH model”, Journal of Applied Econometrics, 11, 23-40.

Ball, L. (1992), "Why does higher inflation raise inflation uncertainty?", Journal of Monetary Economics, 29, 371-378.

Batini, N. (2002), "Euro area inflation persistence", European Central Bank Working Paper Series, No. 201.

Berument, H., Kilinc. Z. and U. Ozlale (2005), "The missing link between inflation uncertainty and interest rates", Scottish Journal of Political Economy, 52, 222-241.

Bofinger, P. (2002), "The EMU after three years: Lessons and challenges", Paper prepared for the Economic Analysis Division of the United Nations Economic Commission for Europe.

Brunner, A.D. (1993), "Comment on 'Inflation regimes and the sources of inflation uncertainty' ", Journal of Money, Credit and Banking, 25, 3 (August, part 2), 512-520.

Brunner, A.D. and G. Hess (1993), “Are higher levels of inflation less predictable? A state-dependent conditional heteroskedasticity approach", Journal of Business and Economic Statistics, 11, 187-197.

Busetti, F., Forni, L., Harvey, A. and F. Venditti (2006), "Inflation convergence and divergence within the European Monetary Union”, European Central Bank Working Paper Series, No. 574.

Commission of the European Communities (2004), "Report on the accountability issue related to the revision of the Greek budgetary data", Communication from the Commission to the European Parliament and the Council.

Conrad, C. and M. Karanasos, (2006), "Dual long memory in inflation dynamics across countries of the Euro area and the link between inflation uncertainty and macroeconomic performance", Studies in Nonlinear Dynamics and Econometrics, forthcoming.

Cukierman, A. and A. Meltzer (1986), "A theory of ambiguity, credibility and inflation under discretion and asymmetric information", Econometrica, 54, 1099-1128.

Davis, G. and B. Kanago (2000), "The level and uncertainty of inflation: results from OECD forecasts", Economic Inquiry, 38, 58-72.

Dickey, D.A. and W.A. Fuller (1979), "Distribution of the estimators for autoregressive time series with a unit root", Journal of the American Statistical Association, 74, 427-431.

Dickey, D.A. and W.A. Fuller (1981), "Likelihood ratio statistics for autoregressive time series with a unit root", Econometrica, 49, 1057-1072.

Engle, R.F. (1982), “Autoregressive conditional heteroskedasticity with estimates of the variance of United Kingdom inflation”, Econometrica, 50, 987-1007.

Engle, R.F. and G. Lee (1993), "A permanent and transitory component model of stock return volatility”, Discussion Paper 92-44R, University of San Diego.

European Central Bank (1999), Monetary Policy Strategy.

European Central Bank (2004), The Monetary Policy of the ECB.

Evans, M. (1991), "Discovering the link between inflation rates and inflation uncertainty", Journal of Money, Credit and Banking, 23, 169-184. 
Evans, M. and P. Wachtel (1993), "Inflation regimes and the sources of inflation uncertainty", Journal of Money, Credit and Banking, 25, 3 (August, part 2), 475-511.

Fountas, S., and M. Karanasos (2006), "Inflation, output growth, and nominal and real uncertainty: empirical evidence for the G7, "Journal of International Money and Finance, forthcoming.

Fountas, S., Ioannidis, A. and M. Karanasos (2004), "Inflation, inflation uncertainty and a common European monetary policy”, Manchester School, 72, 2, 221-242.

Friedman, M. (1977), "Nobel Lecture: Inflation and Unemployment”, Journal of Political Economy, 85, 451-472.

Glosten, L., Jagannathan, R. and D. Runkle (1993), "On the relation between the expected value and the volatility of the normal excess return on stocks", Journal of Finance, 48, 1779-1801.

Grier, K.B. and M.J. Perry (1998), "On inflation and inflation uncertainty in the G7 countries", Journal of International Money and Finance, 17, 671-689.

Grier, K.B. and M.J. Perry (2000), "The effects of real and nominal uncertainty on inflation and output growth: some GARCH-M evidence”, Journal of Applied Econometrics, 15, 45-58.

Heinemann, F. and K. Ullrich (2004), "The impact of EMU on inflation expectations", Discussion Paper no. 04-01, Centre for European Economic Research (ZEW).

Kontonikas, A. (2004), "Inflation and inflation uncertainty in the United Kingdom, evidence from GARCH modelling”, Economic Modelling, 21, 525-543.

Kwiatkowski, D., P. C. B. Phillips, P. Schmidt, and Y. Shin (1992), "Testing the null hypothesis of stationarity against the alternative of a unit root", Journal of Econometrics, 54, 159-178.

Nelson, D.B. (1991), “Conditional heteroskedasticity in asset returns: a new approach”, Econometrica, 59, 347-370.

Newey, W.K. and K.D. West (1994), "Automatic lag selection in covariance matrix estimation", Review of Economic Studies, 61, 4, 631-653.

Pagan, A. (1984), "Econometric issues in the analysis of regressions with generated regressors", International Economic Review, 25, 221-247.

Rapach, D., and C. Weber (2004), "Are real interest rates nonstationary? New evidence from tests with good size and power", Journal of Macroeconomics, 26, 409-430.

Rudebusch, G. and L. Svensson (1999), "Eurosystem monetary targeting: Lessons from U.S. data", Mimeo.

Trichet, J.-C. (2004), "Testimony before the Committee on Economic and Monetary Affairs of the European Parliament (introductory statement).

Zakoian, J. (1994), "Threshold heteroskedastic models", “Journal of Economic Dynamics and Control, 18, 931-944. 
TABLES AND FIGURES

Table 1: Unit Root Tests, 1972-2004

\begin{tabular}{|c|c|c|c|c|}
\hline \multirow{2}{*}{ Countries } & \multicolumn{2}{|c|}{ ADF test statistic } & \multicolumn{2}{c|}{ KPSS test statistic } \\
\cline { 2 - 5 } & Constant & $\begin{array}{c}\text { Constant and } \\
\text { Trend }\end{array}$ & Constant & $\begin{array}{c}\text { Constant and } \\
\text { Trend }\end{array}$ \\
\hline Germany & -2.319 & -2.605 & $2.235 * * *$ & $0.244 * * *$ \\
\hline Italy & -1.144 & $-3.375 *$ & $1.999 * * *$ & $0.273 * * *$ \\
\hline France & -1.461 & -2.896 & $1.646 * * *$ & $0.385 * * *$ \\
\hline Spain & -1.006 & -2.751 & $3.222 * * *$ & $0.451 * * *$ \\
\hline Portugal & -1.579 & $-3.568 * *$ & $2.634 * * *$ & $0.277 * * *$ \\
\hline Greece & -2.006 & -2.704 & $1.845 * * *$ & $0.34 * * *$ \\
\hline Ireland & -1.595 & -2.539 & $2.232 * * *$ & $0.262 * * *$ \\
\hline Finland & -1.181 & -3.132 & $2.037 * * *$ & $0.222 * * *$ \\
\hline Belgium & -1.929 & -2.765 & $2.121 * * *$ & $0.265 * * *$ \\
\hline Netherlands & -1.787 & -1.965 & $2.578 * * *$ & $0.864 * * *$ \\
\hline Luxembourg & -2.438 & -2.523 & $3.195 * * *$ & $0.304 * * *$ \\
\hline Austria & -2.369 & -2.684 & $3.282 * * *$ & $0.301 * * *$ \\
\hline
\end{tabular}

Note:

(a) The number of lagged difference terms in the regressions was chosen by the modified Akaike criterion in the ADF regressions. The Andrews bandwidth was used in the KPSS regressions.

(b) The reported ADF statistics test the null hypothesis that inflation contains a unit root. The reported KPSS statistics test the null hypothesis that inflation is stationary.

(c) $* * *, * *, *$ indicate rejection of the null hypothesis at $1,5,10 \%$ level of significance. 
Table 2: Robust estimates of Eq. (11), 1980-2004

\begin{tabular}{|c|c|c|c|c|c|c|c|c|}
\hline & \multicolumn{2}{|c|}{ Germany } & \multicolumn{2}{|c|}{ France } & \multicolumn{2}{|c|}{ Italy } & \multicolumn{2}{|c|}{ Spain } \\
\hline & $\sigma_{t}^{2}\left(\pi_{t+1}^{*}\right)$ & $H_{t}$ & $\sigma_{t}^{2}\left(\pi_{t+1}^{*}\right)$ & $H_{t}$ & $\sigma_{t}^{2}\left(\pi_{t+1}^{*}\right)$ & $H_{t}$ & $\sigma_{t}^{2}\left(\pi_{t+1}^{*}\right)$ & $H_{t}$ \\
\hline$\gamma_{0}$ & -0.001 & 0.0002 & -0.0004 & 0.008 & 0.002 & -0.003 & $0.004 *$ & -0.001 \\
\hline$\gamma_{1}$ & 0.002 & -0.00006 & 0.001 & -0.020 & $0.031 *$ & 0.003 & 0.130 & 0.003 \\
\hline$\gamma_{2}$ & 0.009 & $0.1 * * *$ & $0.049 * *$ & $0.329 *$ & $0.099 *$ & -0.039 & -0.004 & 0.029 \\
\hline$\gamma_{3}$ & $-0.015 *$ & $-0.106 * *$ & $-0.045 * *$ & 0.047 & $-0.235 * *$ & 0.041 & $-1.187 * * *$ & -0.037 \\
\hline$R^{2}$ & 0.044 & 0.225 & 0.215 & 0.084 & 0.165 & 0.052 & 0.22 & 0.032 \\
\hline$\sigma_{\theta}$ & 0.013 & 0.05 & 0.021 & 0.317 & 0.078 & 0.049 & 0.674 & 0.076 \\
\hline $\begin{array}{c}\text { Wald F-stat } \\
\gamma_{2}+\gamma_{3}=0\end{array}$ & - & 0.053 & $10.352 * * *$ & - & $3.306 *$ & - & - & - \\
\hline
\end{tabular}

\begin{tabular}{|c|c|c|c|c|c|c|c|c|}
\hline & \multicolumn{2}{|c|}{ Portugal } & \multicolumn{2}{|c|}{ Greece } & \multicolumn{2}{|c|}{ Ireland } & \multicolumn{2}{|c|}{ Finland } \\
\hline & $\sigma_{t}^{2}\left(\pi_{t+1}^{*}\right)$ & $H_{t}$ & $\sigma_{t}^{2}\left(\pi_{t+1}^{*}\right)$ & $H_{t}$ & $\sigma_{t}^{2}\left(\pi_{t+1}^{*}\right)$ & $H_{t}$ & $\sigma_{t}^{2}\left(\pi_{t+1}^{*}\right)$ & $H_{t}$ \\
\hline$\gamma_{0}$ & 0.0001 & -0.007 & 0.001 & -0.009 & -0.0001 & -0.005 & -0.0003 & -0.002 \\
\hline$\gamma_{1}$ & 0.002 & 0.004 & -0.001 & 0.009 & 0.0001 & 0.008 & 0.0001 & 0.004 \\
\hline$\gamma_{2}$ & $0.023 * * *$ & $0.052 *$ & -0.0004 & $0.038 *$ & -0.00002 & $0.109 * *$ & 0.0025 & 0.001 \\
\hline$\gamma_{3}$ & 0.005 & -0.028 & $-0.005 * * *$ & $-0.036 *$ & $0.0007 * * *$ & $-0.107 * *$ & 0.0012 & -0.011 \\
\hline$R^{2}$ & 0.177 & 0.054 & 0.076 & 0.092 & 0.101 & 0.115 & 0.028 & 0.019 \\
\hline$\sigma_{\theta}$ & 0.042 & 0.169 & 0.007 & 0.106 & 0.002 & 0.338 & 0.007 & 0.026 \\
\hline $\begin{array}{c}\text { Wald F-stat } \\
\gamma_{2}+\gamma_{3}=0\end{array}$ & - & - & - & 0.049 & - & 0.02 & - & - \\
\hline
\end{tabular}




\begin{tabular}{|c|c|c|c|c|c|c|c|c|}
\hline & \multicolumn{2}{|c|}{ Belgium } & \multicolumn{2}{c|}{ Netherlands } & \multicolumn{2}{c|}{ Luxembourg } & \multicolumn{2}{c|}{ Austria } \\
\cline { 2 - 9 } & $\sigma_{t}^{2}\left(\pi_{t+1}^{*}\right)$ & $H_{t}$ & $\sigma_{t}^{2}\left(\pi_{t+1}^{*}\right)$ & $H_{t}$ & $\sigma_{t}^{2}\left(\pi_{t+1}^{*}\right)$ & $H_{t}$ & $\sigma_{t}^{2}\left(\pi_{t+1}^{*}\right)$ & $H_{t}$ \\
\hline$\gamma_{0}$ & -0.0003 & -0.0004 & 0.0005 & -0.00001 & 0.00007 & -0.002 & 0.0005 & 0.0002 \\
\hline$\gamma_{1}$ & 0.001 & 0.001 & 0.0002 & 0.0002 & 0.002 & 0.002 & $0.002 * *$ & 0.0001 \\
\hline$\gamma_{2}$ & $0.013 * * *$ & -0.011 & -0.024 & -0.03 & $0.025^{*}$ & 0.001 & $0.004 * * *$ & 0.002 \\
\hline$\gamma_{3}$ & $-0.01 * * *$ & 0.008 & 0.020 & 0.066 & $-0.026^{*}$ & -0.002 & $-0.004 * *$ & -0.0002 \\
\hline$R^{2}$ & 0.136 & 0.03 & 0.033 & 0.071 & 0.033 & 0.001 & 0.133 & 0.005 \\
\hline$\sigma_{\theta}$ & 0.01 & 0.02 & 0.041 & 0.045 & 0.048 & 0.037 & 0.004 & 0.014 \\
\hline $\begin{array}{c}\text { Wald F-stat } \\
\gamma_{2}+\gamma_{3}=0\end{array}$ & $34.313^{* * *}$ & - & - & - & 0.188 & - & 0.002 & - \\
\hline
\end{tabular}

Note: $\sigma_{\theta}$ represents the standard deviation of the regression's residuals. 
Figure 1: Actual inflation and steady-state inflation, 1980-2004.
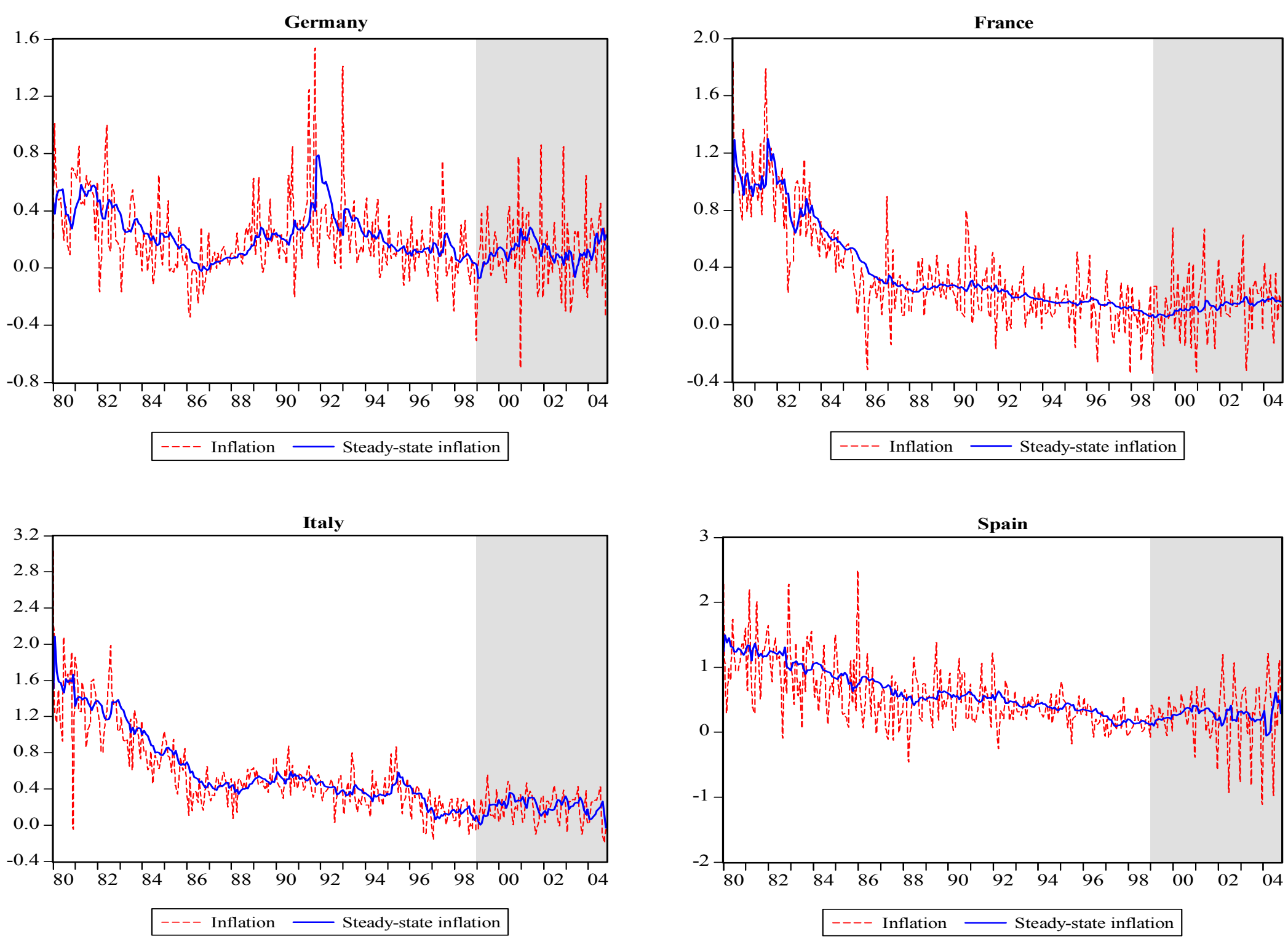
Portugal

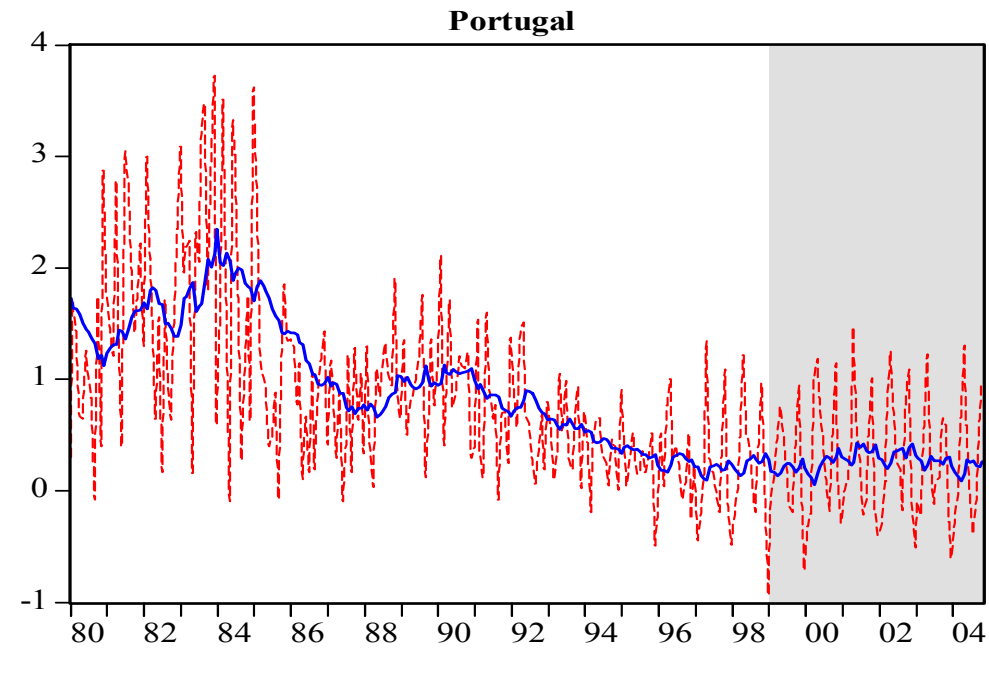

---- Inflation - Steady-state inflation

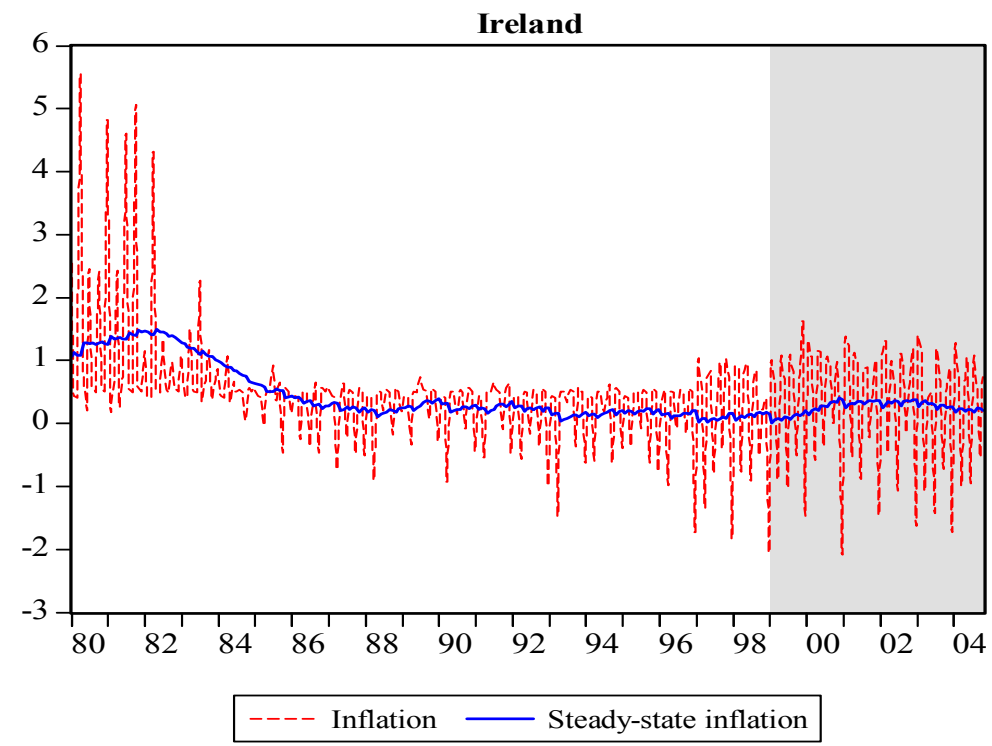

Greece

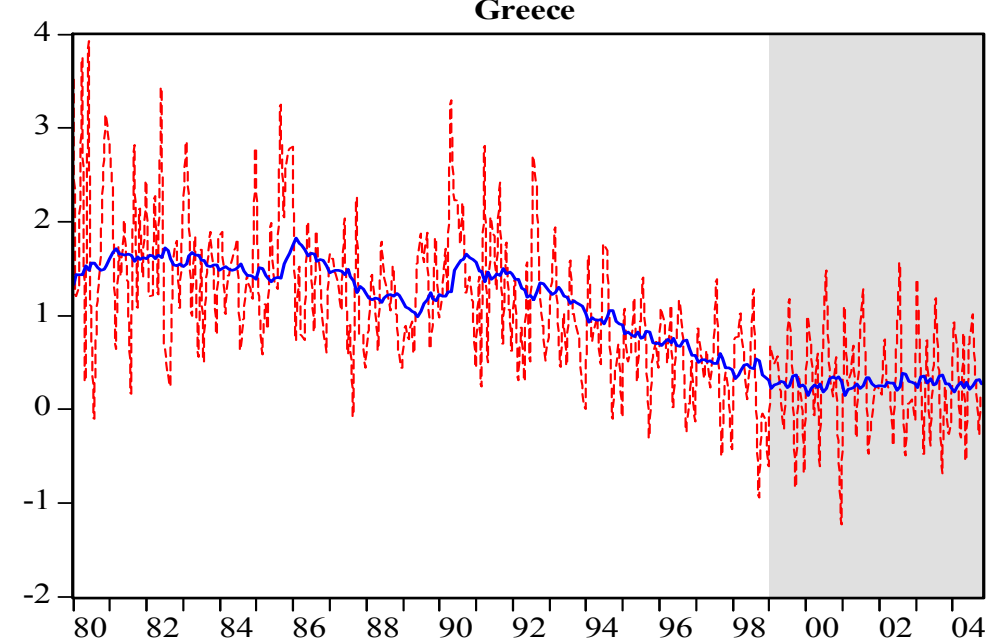

---- Inflation $\longrightarrow$ Steady-state inflation

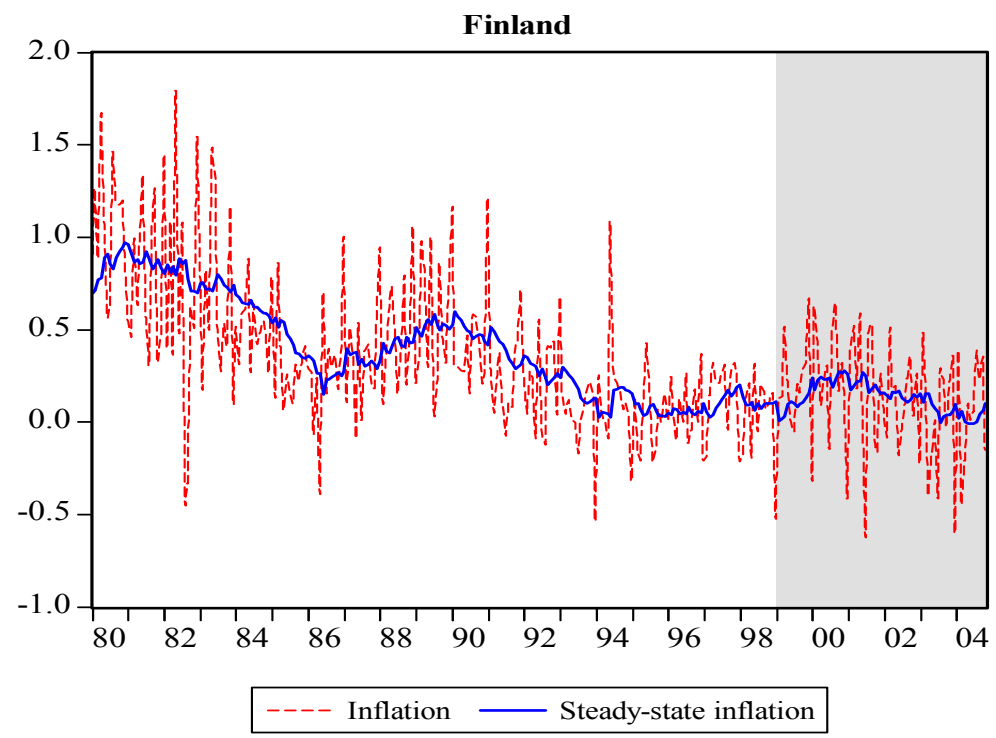


Belgium

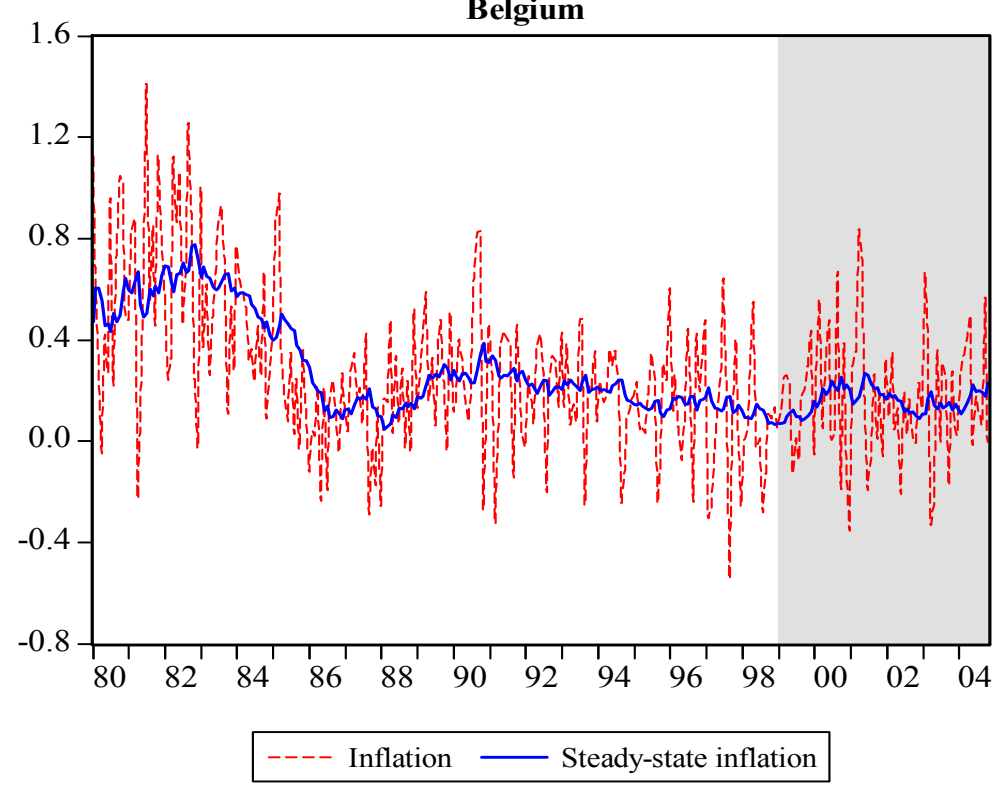

Luxembourg

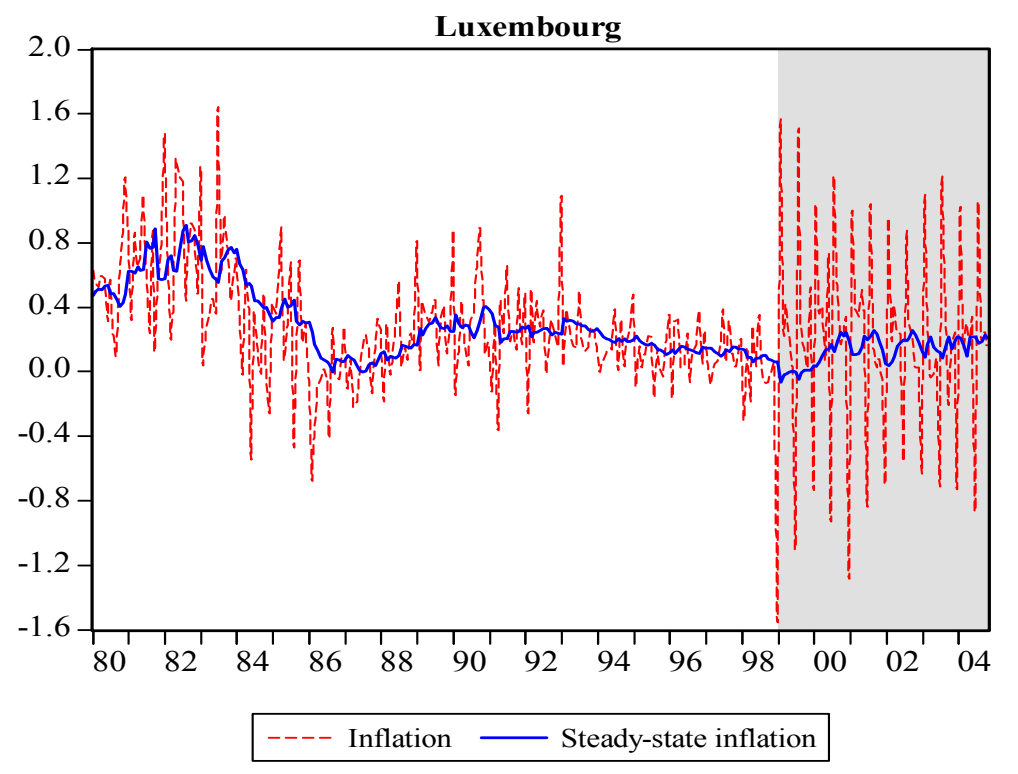

Netherlands

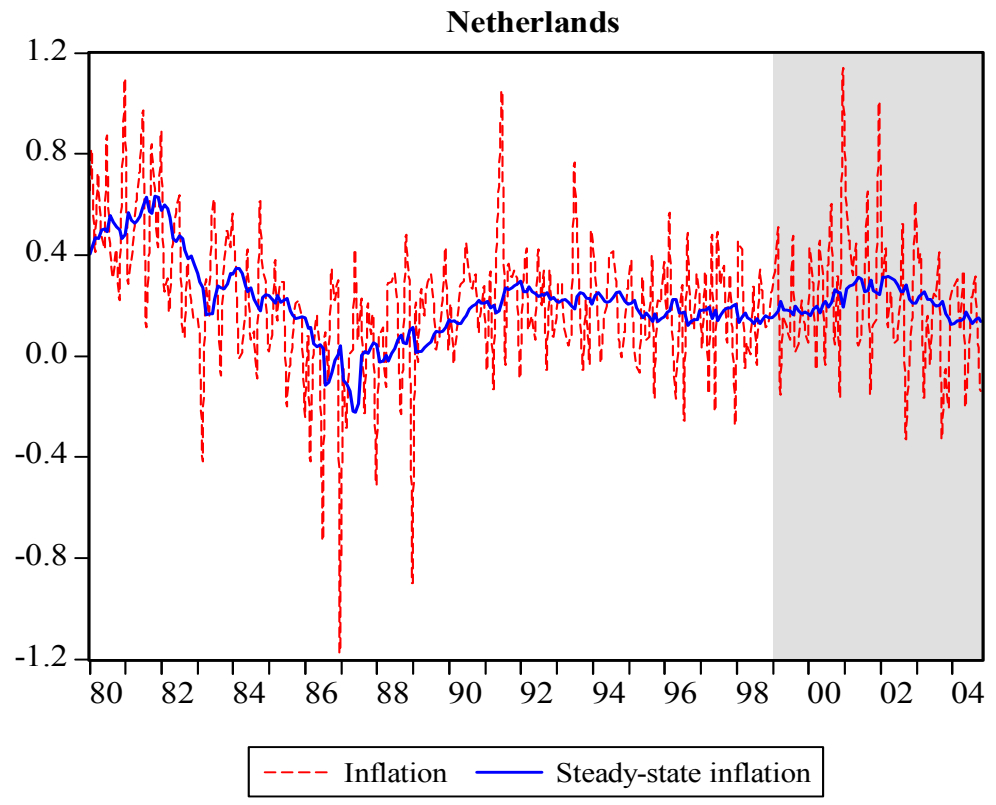

Austria

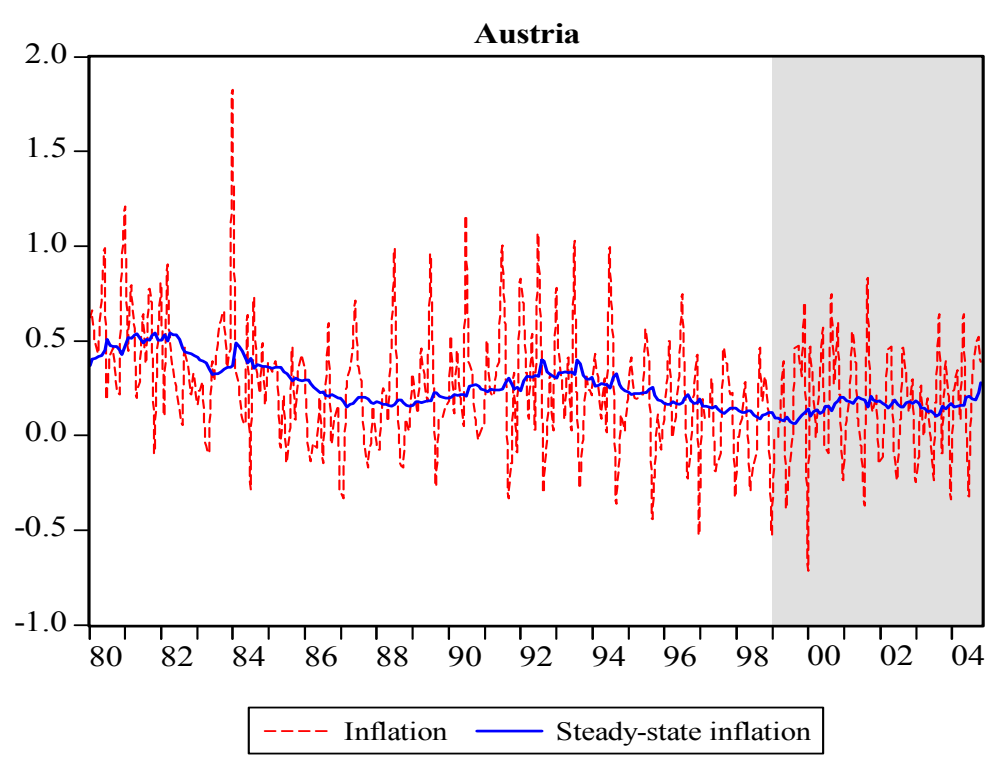


Figure 2: Short-run and steady-state inflation uncertainty, 1980-2004.
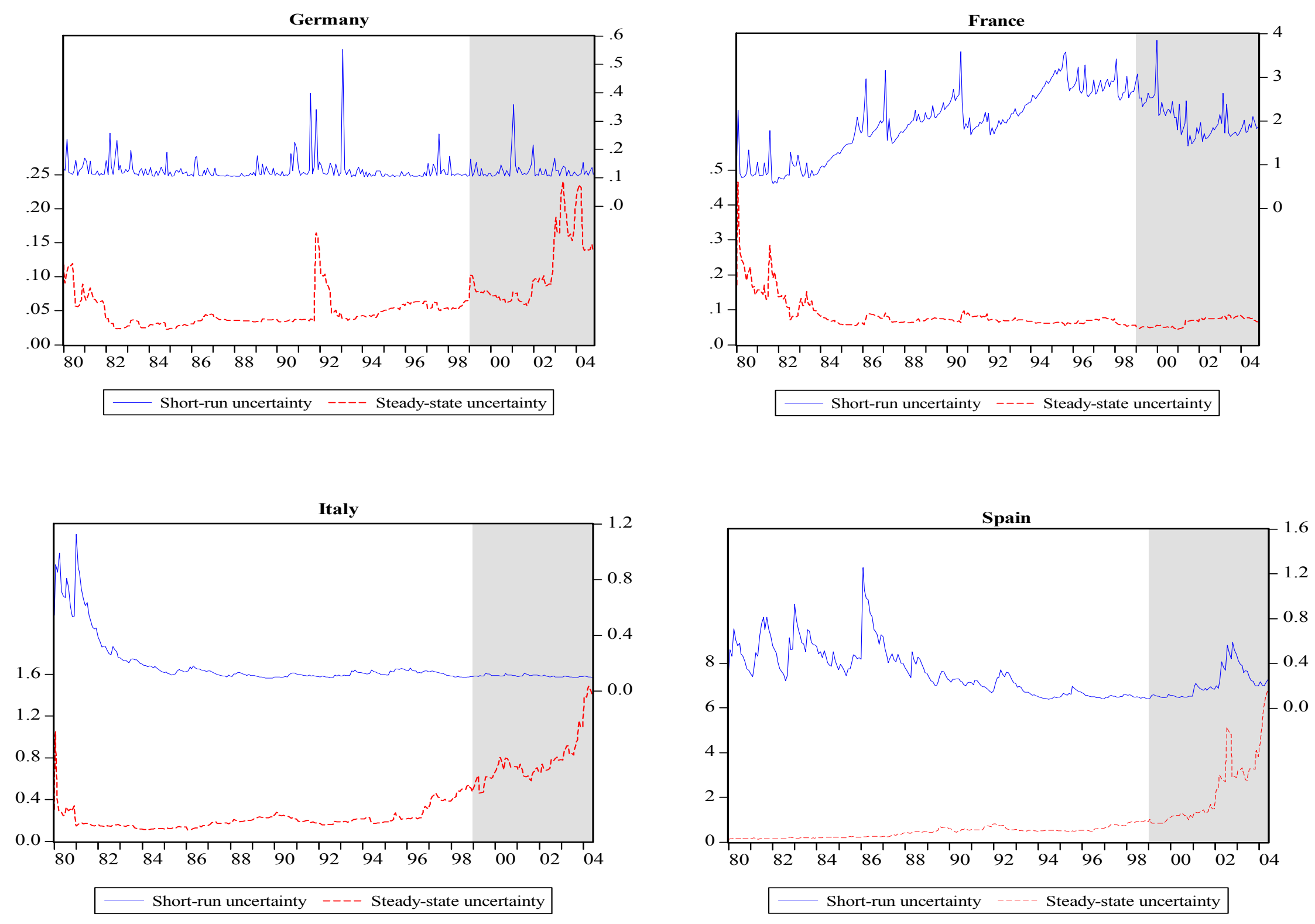

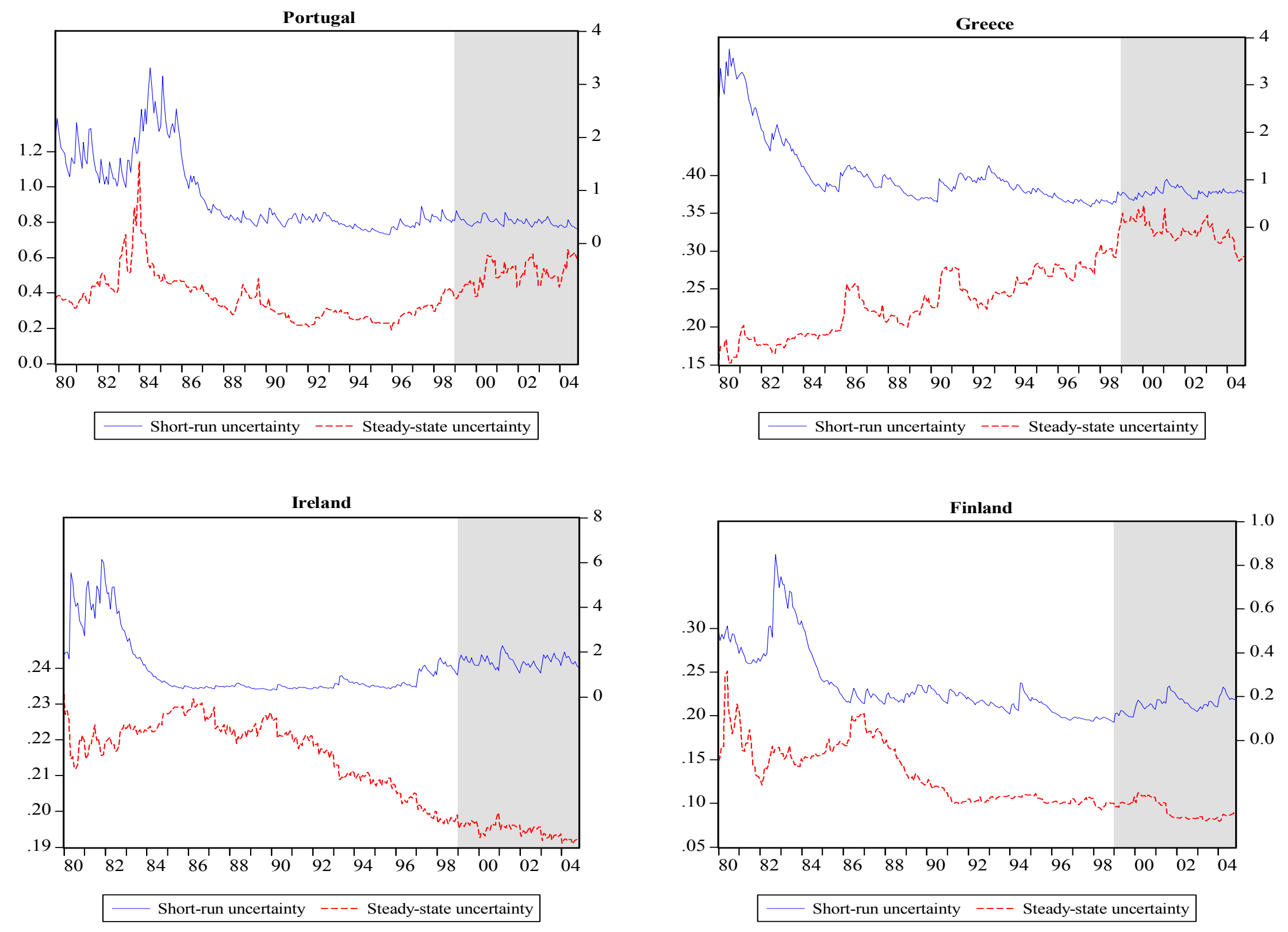

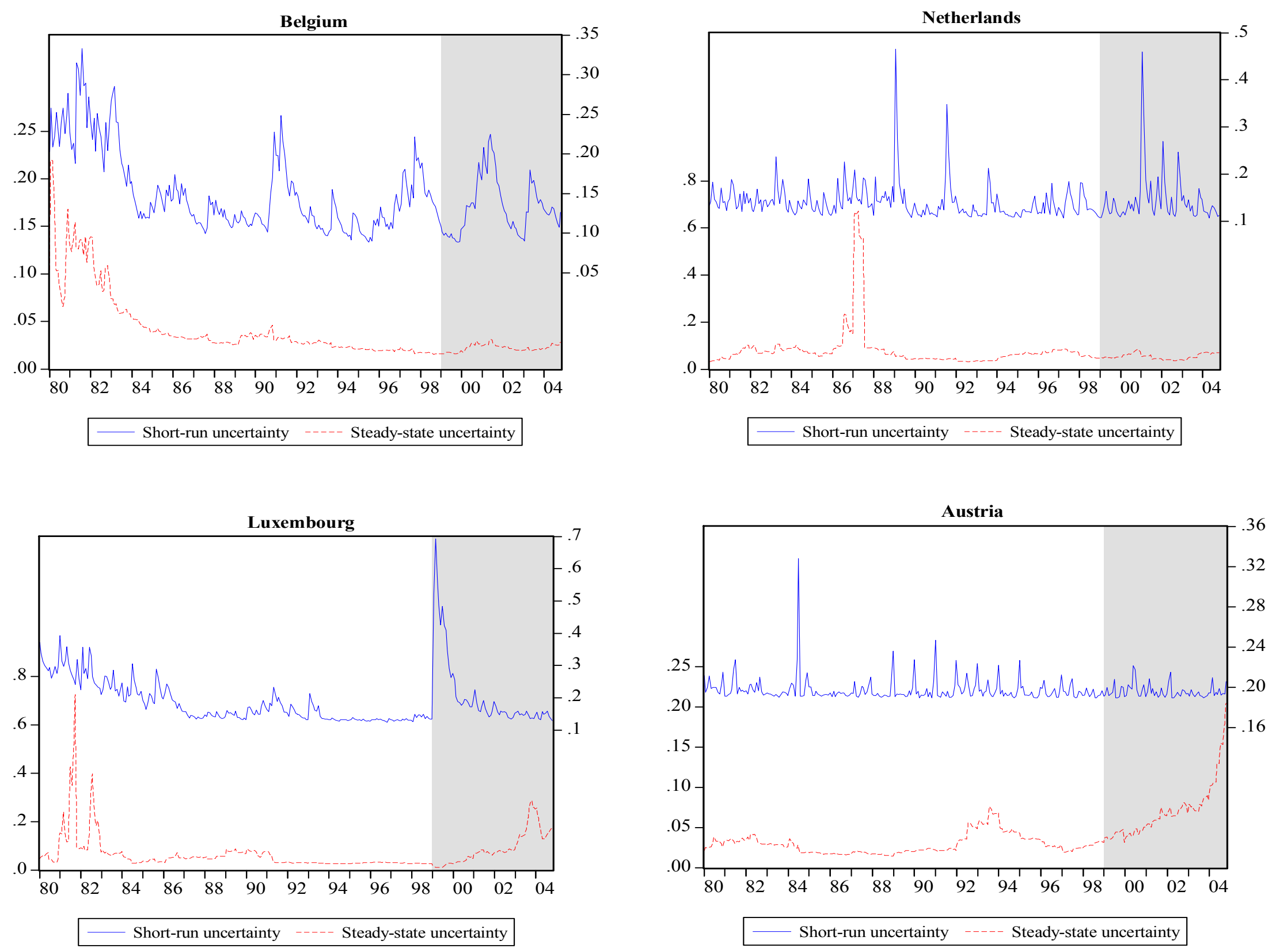
Figure 3: Inflation persistence and trend inflation, 1980-2004.
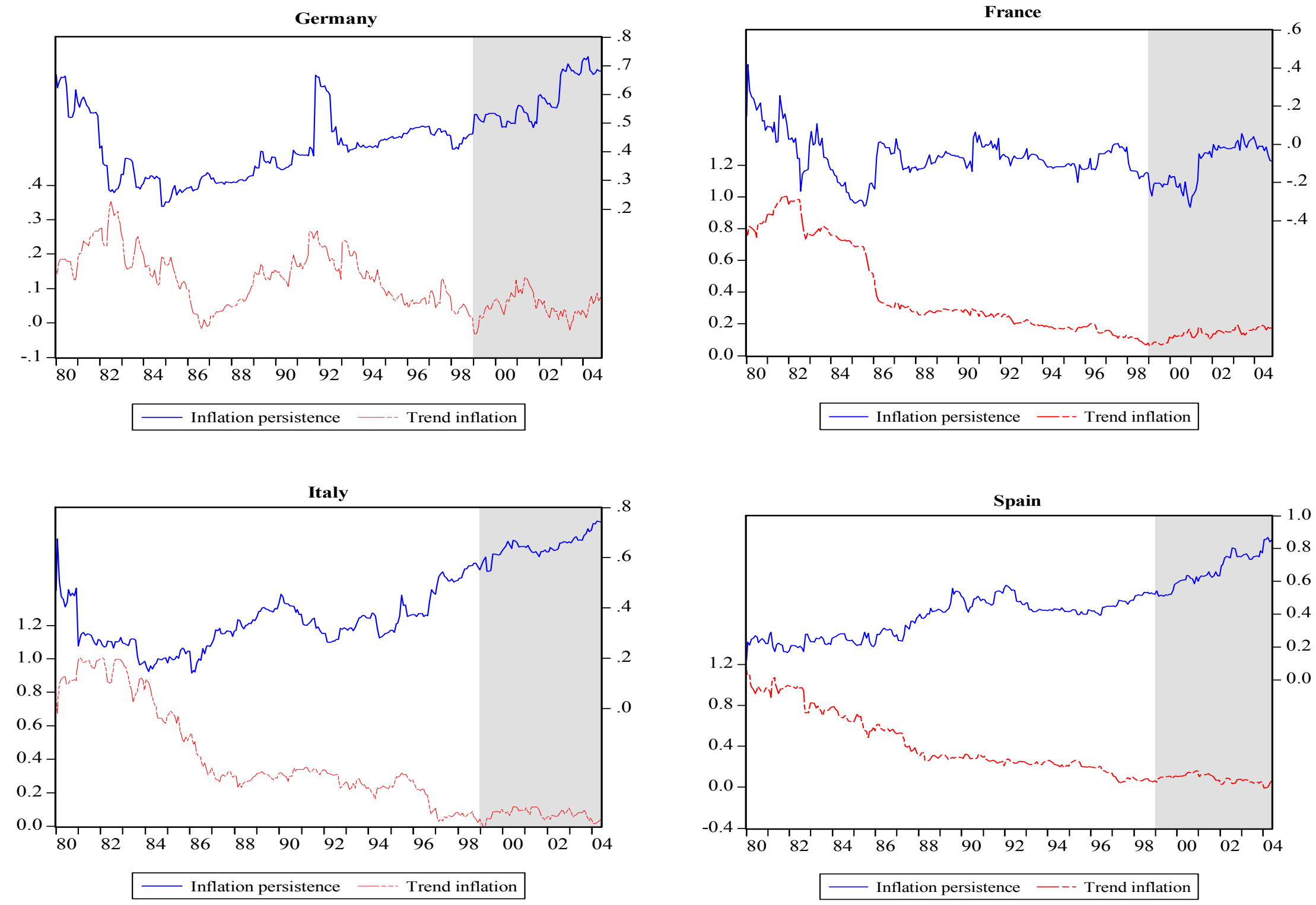

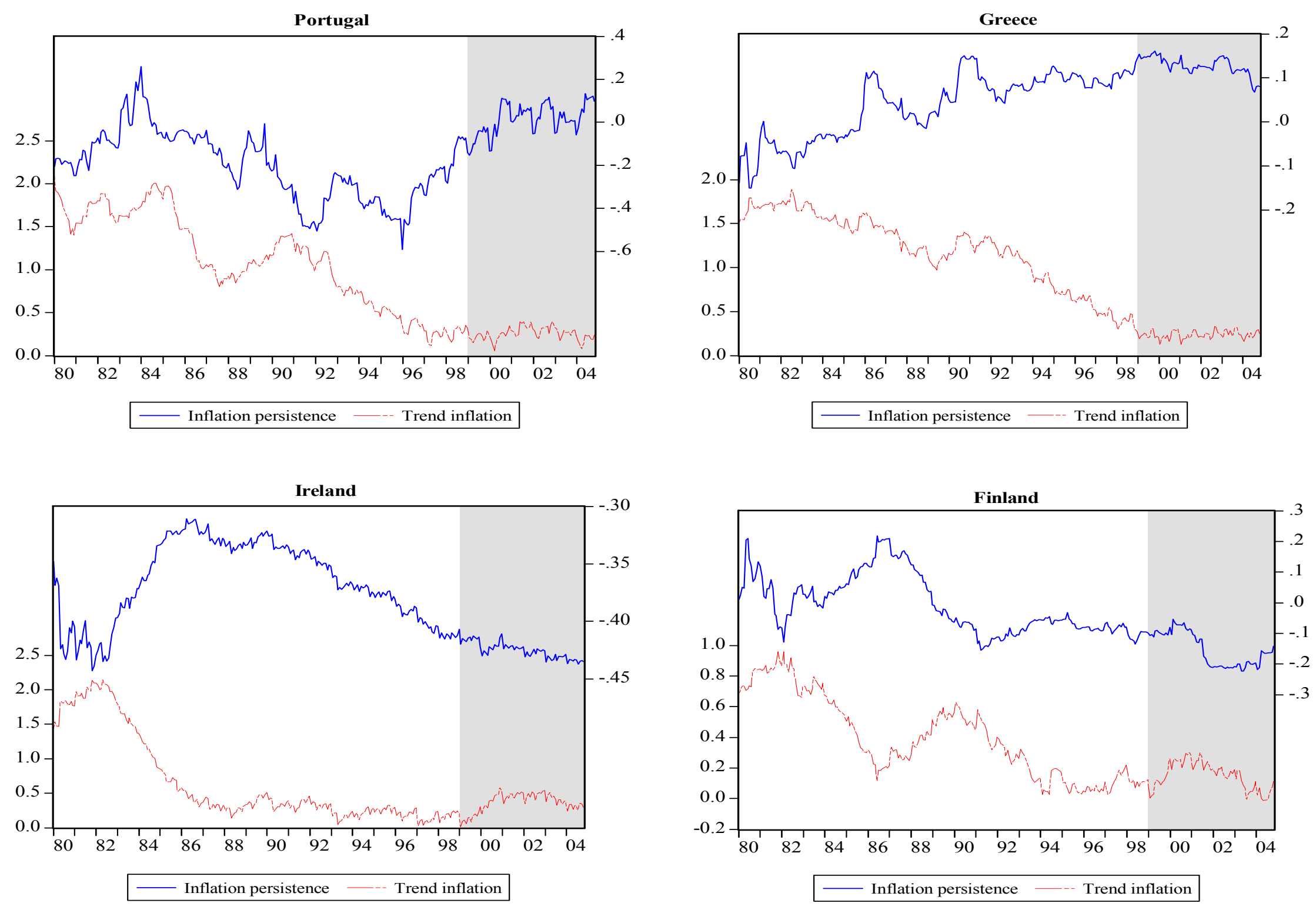

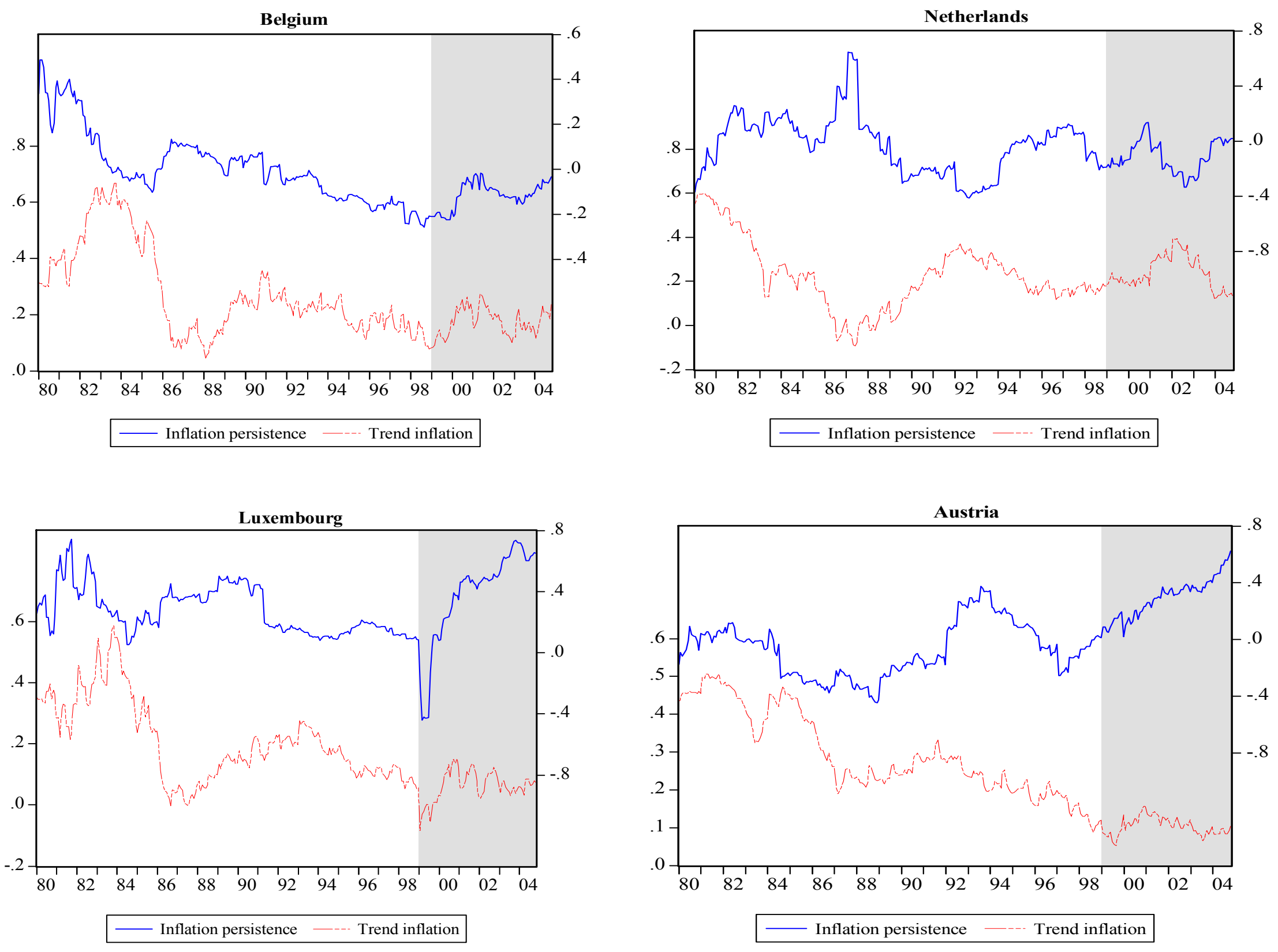